\title{
SHIFTING PREY SELECTION GENERATES CONTRASTING HERBIVORE DYNAMICS WITHIN A LARGE-MAMMAL PREDATOR-PREY WEB
}

\author{
Norman Owen-Smith ${ }^{1,3}$ and M. G. L. Mills ${ }^{2}$ \\ ${ }^{1}$ Centre for African Ecology, School of Animal, Plant and Environmental Sciences, University of the Witwatersrand, \\ Wits 2050 South Africa \\ ${ }^{2}$ The Tony and Lisette Lewis Foundation, South Africa, and Mammal Research Institute, University of Pretoria, \\ Private Bag X890, Upington, South Africa
}

\begin{abstract}
Shifting prey selection has been identified as a mechanism potentially regulating predator-prey interactions, but it may also lead to different outcomes, especially in more complex systems with multiple prey species available. We assessed changing prey selection by lions, the major predator for 12 large herbivore species in South Africa's Kruger National Park. The database was provided by records of found carcasses ascribed to kills by lions assembled over 70 years, coupled with counts of changing prey abundance extending over 30 years. Wildebeest and zebra constituted the most favored prey species during the early portion of the study period, while selection for buffalo rose in the south of the park after a severe drought increased their vulnerability. Rainfall had a negative influence on the proportional representation of buffalo in lion kills, but wildebeest and zebra appeared less susceptible to being killed under conditions of low rainfall. Selection by lions for alternative prey species, including giraffe, kudu, waterbuck, and warthog, was influenced by the changing relative abundance and vulnerability of the three principal prey species. Simultaneous declines in the abundance of rarer antelope species were associated with a sharp increase in selection for these species at a time when all three principal prey species were less available. Hence shifting prey selection by lions affected the dynamics of herbivore populations in different ways: promoting contrasting responses by principal prey species to rainfall variation, while apparently being the main cause of sharp declines by alternative prey species under certain conditions. Accordingly, adaptive responses by predators, to both the changing relative abundance of the principal prey species, and other conditions affecting the relative vulnerability of various species, should be taken into account to understand the interactive dynamics of multispecies predator-prey webs.
\end{abstract}

Key words: food web dynamics; Kruger National Park, South Africa; lion; multispecies systems; Panthera leo; predation; prey preferences; resource selection.

\section{INTRODUCTION}

Predation can have either stabilizing or destabilizing effects on prey dynamics, depending on how the predator responds to changes in prey abundance (Fryxell and Lundberg 1994, Ballard et al. 2001). In single-prey systems, a hyperbolic (Type II) intake rate (or "functional") response is destabilizing because the predator removes a smaller proportion of the prey population as food-processing capacity per predator becomes saturated toward high prey abundance levels. Furthermore, a delay in the numerical response of the predator population to changing prey abundance leads to coupled oscillations by the two populations (Hanski et al. 1991). With two prey species available, the predator can switch its prey selection between them depending on relative prey availability. Switching generates an initially accelerating (Type III) intake response, counteracting fluctuations in prey abundance by reducing the proportion predated when prey abun-

Manuscript received 19 June 2007; revised and accepted 13 August 2007. Corresponding Editor: J. M. Fryxell.

${ }^{3}$ E-mail: Norman.Owen-Smith@wits.ac.za dance declines below some level (van Boalen et al. 2001). In certain circumstances, a Type III intake response may limit prey populations below the ceiling set by food resources (Fryxell et al. 1988, Messier 1994). If the predator population is maintained by an abundant principal prey, the alternative prey species could be restricted to low abundance levels (Bergerud and Elliot 1986), or even driven toward extinction (Wittmer et al. 2005). Persistence of these prey may be ensured if spatial variation in habitat conditions makes some segment of the prey population less susceptible to predation (Matter and Mannan 2005).

Applying these theoretical concepts becomes more challenging when multiple prey species are available, and particularly when the susceptibility of these species to predation depends on environmental conditions. Accordingly, relatively few studies have documented the interactive dynamics of more complex food webs (de Ruiter et al. 2005). Large-mammal assemblages in African savannas may contain over 20 herbivore species exceeding $10 \mathrm{~kg}$ in adult body mass, and five carnivore species within a similar size range. Several studies have highlighted the substantial top-down impacts that 
predation can have on herbivore populations in these systems (Mills et al. 1995, Harrington et al. 1999, Sinclair et al. 2003, Ogutu and Owen-Smith 2005, Funston and Mills 2006, Grange and Duncan 2006). Changing rainfall conditions influence both food resources and vegetation cover, and consequently the vulnerability of these herbivores to predation (Smuts 1978, Mills et al. 1995). Changing prey availability also affects predator abundance. Correlative evidence suggests that a putative increase in the abundance of lions (Panthera leo) was primarily responsible for drastic declines in the populations of several less common ungulate species in South Africa's Kruger National Park (KNP; Harrington et al. 1999, Owen-Smith and Mills 2006). However, a contributory influence from adverse habitat conditions following a period of low rainfall could not be excluded.

In this paper, we investigate whether shifts in relative prey selection by lions in response to changing conditions contributed in an additive way to the changing abundance of herbivore populations in KNP. The database was provided by records of animal carcasses and the apparent cause of death gathered routinely by field staff (Pienaar 1969). An earlier analysis of a portion of these data showed that certain ungulate species featured more prominently in lion kills during periods of low rainfall, while others tended to be predated more at times of high rainfall (Mills et al. 1995). We extend their treatment to encompass the entire park, and all 12 ungulate species for which reliable estimates of changes in abundance were available (excluding megaherbivores that rarely form prey).

The mechanism underlying a Type III functional response is switching away from the initially favored prey species when its availability becomes sufficiently low. However, complete switching occurs only when alternative prey species are found in different places, so that while searching for one species, the predator does not encounter the other species (Schmitz 1995). In more complex systems where prey species overlap in their distributions, changing prey selection is likely to be revealed by shifts in relative use by the predator. Distinctions should exist between the principal prey species, which constitute the greatest portion of the diet under normal conditions, and alternative, generally less abundant prey species, sought out when the principal species become less available. Specifically, we expect that:

1) Selection for principal prey species should decline when they become less common, and hence depend positively on their own population abundance.

2) Selection for less common species should be negatively related to the abundance of the principal species, and largely independent of their own abundance.

Alternatively, if environmental conditions affecting vulnerability to predation exert an overriding influence, prey selection should depend more on the salient factors and less on the changing abundance of the prey species. In particular, if susceptibility to predation depends on body condition, governed by food resources (Sinclair and Arcese 1995), and plant growth responds positively to rainfall (Rutherford 1980), we expect that:

3) Selection for food-limited prey species should be negatively related to the preceding rainfall conditions.

On the other hand, if prey vulnerability depends instead on the vegetation cover providing concealment for stalking predators (Smuts 1978), related in turn to grass height, we expect that:

4) Selection for these prey species should be positively related to rainfall during the preceding growing season.

Whatever the agent of mortality, vulnerability to predation should depend on the effective food availability and hence increase toward higher prey density levels (Sinclair and Arcese 1995). Consequently we expect that:

5) Selection for food-limited prey should be positively related to the abundance of these prey species toward high abundance levels.

Following on from this, if food availability is affected by interspecific competition in addition to intraspecific competition, we expect that:

6) Selection for prey species that are inferior competitors should be negatively related to the abundance of the superior competitors.

Prediction 6 is essentially identical to prediction 2, which is why direct competition for food resources cannot be distinguished phenomenologically from "apparent competition" mediated through a shared predator (Holt 1977).

Accordingly, different combinations of factors should affect different species within the prey assemblage, resulting in contrasting outcomes in terms of population dynamics. More specifically, if shifting prey selection influences population dynamics, a relationship should exist between changes in the prey population between one year and the next, and changes in selection by the predator for this species.

\section{Methods \\ The database}

Records of the carcasses of all animals found dead, and the apparent cause of death, were collected routinely by field staff in KNP from 1936 to 1946 and then from 1954 until recording faded out after 1995. The amalgamated data prior to 1966 were extracted from Pienaar (1969). Subsequent records were obtained from the database held by the Scientific Services division of South African National Parks. For only 6\% of 49453 carcasses was death ascribed to a cause other than predation (Owen-Smith and Mills 2008). Lions were responsible for $55 \%$ of the recorded kills, and other predators, including spotted hyena (Crocuta crocuta), leopard (Panthera pardus), cheetah (Acinonyx jubatus), and African wild dog (Lycaon pictus), for the remainder.

The first reliable estimates of animal populations within KNP were presented by Pienaar (1963), and the 
first aerial count took place in 1965. Further aerial counts were conducted irregularly until 1975, and then annually from 1977 to 1996 , covering almost the entire $19500-\mathrm{km}^{2}$ extent of the park from 1980 to 1993 (Joubert 1983, Viljoen and Retief 1994). The 12 prey species we considered were, in order of their numerical abundance, impala (Aepyceros melampus), African buffalo (Syncerus caffer), Burchell's zebra (Equus burchelli), blue wildebeest (Connochetes taurinus), greater kudu (Tragelaphus strepsiceros), giraffe (Giraffa camelopardalis), common waterbuck (Kobus ellipsiprymnus), warthog (Phacochoerus aethiopicus), sable antelope (Hippotragus niger), tsessebe (Damaliscus lunatus), eland (Taurotragus oryx), and roan antelope (Hippotragus equinus). Although impala are numerically the most frequently recorded prey of lions, wildebeest, zebra, and buffalo generally constitute the principal prey species in terms of dietary contribution by mass (Owen-Smith and Mills 2008). Ungulates $<50 \mathrm{~kg}$ in adult body mass, apart from impala, were not considered in the prey base, because reliable population estimates were not available for them. They contributed $<2 \%$ of the kill records for lions. Kill records for 1936-1946 and 1954-1965 were treated as composite blocks, because data on changing herbivore populations during these periods were unavailable. The four rare antelope species, i.e., sable, tsessebe, eland, and roan, were combined into one category for analysis, because they showed similar trends while being too sparse numerically for reliable estimates of annual variation in their individual kill records.

Culling contributed to changes in wildebeest and zebra numbers between 1965 and 1974 (Smuts 1978, Whyte and Joubert 1988), while culling restricted the growth of the buffalo population from 1969 until 1992. Annual rainfall totals (July-June) were obtained from records made at ranger stations distributed throughout the park.

\section{Adjustments to the records}

Both the carcass records and aerial counts are biased against smaller and hence less visible animals. These biases are of little relevance where our concern is merely with the changing proportional representation of prey species over time. We need assume only that such biases remained constant. Accordingly, we included prey of all age classes in the analysis, despite the under-recording of juvenile ungulates in the data (in contrast to the treatment of the same data by Owen-Smith and Mills [2008]).

For graphical depictions, we suppressed random counting errors using weighted running means, calculated as $0.5 N_{t}+0.25 N_{t-1}+0.25 N_{t+1}$, where $t$ is the census year and $N_{t}$ represents the total count for that year (following Owen-Smith and Mills 2006). Annual records of the number of carcasses of animals killed by predators for each prey species were also smoothed using the same weighted average. The smoothed data were used to index comparative variability in prey populations and kill proportions, in terms of the range and coefficient of variation (CV) around the mean over the period between 1960 and 1996. However, for fitting statistical models we used the original, untransformed records to ensure the independence of the data used.

\section{Assessing relative selection}

The degree of selection by consumers for particular resource types is commonly assessed using the relation between proportional availability and proportional use (the selection ratio), or some transformation thereof (Manly et al. 2002). This crudely indexes the underlying probability that a particular prey type will be captured and consumed when encountered (Chesson 1978, 1983). The selection ratio is the composite outcome of all of the processes affecting prey capture, i.e., where predators search, how the herd size of the prey species affects encounters, the frequency with which a hunt is launched when potential prey are detected, and the chance that the hunt will successfully result in a kill. Most problematic is the estimate of availability, especially when there is a wide range of potentially usable resource types and infrequent use of many of them. In these circumstances, distinguishing positive from negative selection by relating values to a null model of unselective use can be misleading, because the null value depends on the range of prey types deemed to be available. Nevertheless, selection ratios and simple transformations thereof (e.g., Chesson's $\alpha_{i}$ ) retain the basic property of indicating relative probabilities of use of alternative prey types, given the underlying assumptions about relative availability (Manly et al. 2002).

To compare the changing relative selection by lions for particular prey species directly, we transformed the crude selection ratios into the "relative kill likelihood." We assigned the most favored prey species a kill likelihood of 1.0, and calculated comparative values for other species as a proportion of this maximum. Values will be altered either if the probability of a kill being made changes for the most favored prey, or for these other species. Hence values are subject to stochastic uncertainty when the most favored prey happens to be an uncommon species for which estimates of the selection ratio are imprecise.

Measures of relative prey selection are also affected by biases that may exist in the data. Crude selection ratios exaggerate selection for the species that are less readily visible from the air, and hence subject to greater undercounting bias. Kudu and waterbuck fall into this category. Selection ratios for giraffe and buffalo are exaggerated because their large carcasses last longest and hence are more likely to be found than those of smaller species. Accordingly, prior to deriving relative kill likelihoods we adjusted the data for both availability and use to suppress these biases, using the factors provided in supplementary tables S1 and S2 to OwenSmith and Mills (2008). To reduce stochastic distortions, 


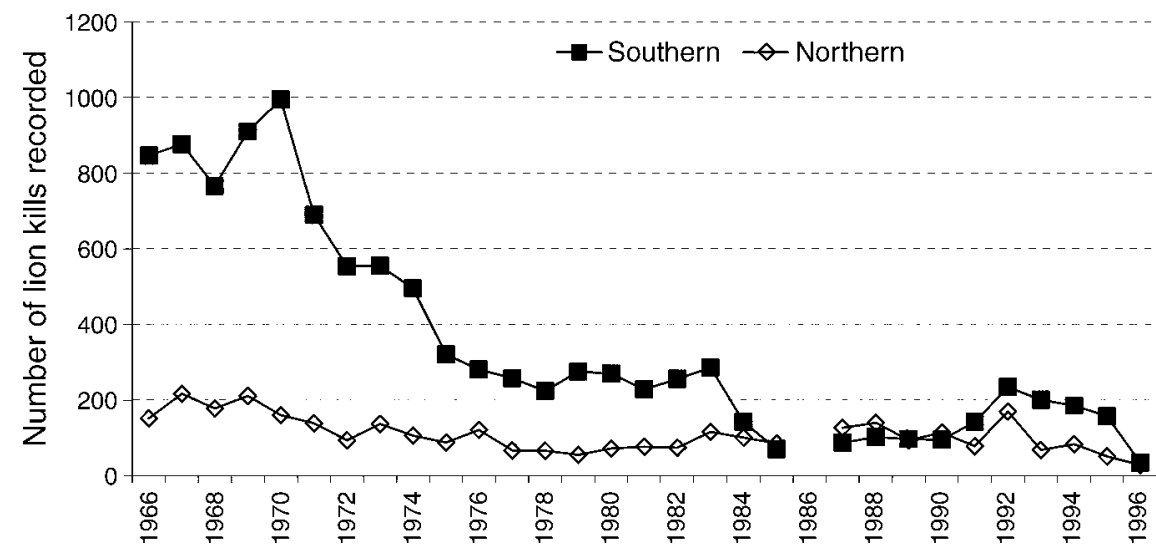

FIG. 1. Trends in annual sample size of records of lions kills in the Kruger National Park. Data shown are for northern and southern regions of the park.

we combined kudu and waterbuck into one category, and ignored estimates for warthog or the rare antelope species when assigning the most highly selected species.

\section{Statistical models}

To relate changing prey selection to potentially influential factors, we used the $\log _{10}$ values of crude selection ratios derived from the untransformed annual population totals and carcass records. Models were fitted using general linear models in SYSTAT 8.0 (SPSS 1998). The factors considered included (1) the region of the park (southern or northern half), (2) period (either preceding or following the severe drought of 1982 1983), (3) current abundance of the prey species relative to its mean abundance, (4) current abundance of principal prey species relative to their mean values, and (5) prior rainfall, expressed as the log-transform of values relative to their mean. Rainfall was considered either (a) over the immediately preceding annual cycle, (b) averaged over the two preceding annual cycles, or (c) as a weighted average over the preceding three years. We used a hypothesis-testing approach based on $P<0.05$ to decide on the joint set of factors to incorporate into the model. Marginal $P$ values are also reported for other factors included additionally in the model incorporating the basic set of significant predictors. We report regression coefficients for continuous predictors separately for the northern and southern halves of the park, if the regional distinction proved significant, as well as mean values for the logged selection ratios for the two regions in such instances. The factors considered are not independent, e.g., a change in the abundance of any one prey species affects the proportional abundance of other species, and hence the calculated values for the selection ratio. Hence primary interest lies in the differences between the prey species in the patterns shown, rather than in the questionable $P$ values. The data sets used in fitting these models are lodged at the South African

TABLE 1. Data for prey species ranked in order of their numerical population size.

\begin{tabular}{lrcccc}
\hline \hline \multicolumn{1}{c}{ Prey } & $\begin{array}{c}\text { Mean } \\
\text { numbers }\end{array}$ & Range & $\begin{array}{c}\text { Ratio in } \\
\text { abundance } \dagger\end{array}$ & $\begin{array}{c}\text { CV in } \\
\text { population }\end{array}$ & $\begin{array}{c}\text { CV in kill } \\
\text { proportion }\end{array}$ \\
\hline Impala & 105000 & $80000-135000$ & 1.7 & 0.132 & 0.345 \\
Buffalo & 25000 & $10550-32700$ & 3.1 & 0.231 & 0.436 \\
Zebra & 23800 & $13000-32100$ & 2.5 & 0.276 & 0.229 \\
Wildebeest & 11800 & $7700-15500$ & 2.0 & 0.208 & 0.339 \\
Kudu & 7000 & $2780-10200$ & 3.7 & 0.319 & 0.434 \\
Giraffe & 4135 & $2350-5450$ & 2.3 & 0.225 & 0.339 \\
Waterbuck & 2900 & $1290-4350$ & 3.4 & 0.280 & 0.236 \\
Warthog & 2790 & $650-4330$ & 6.7 & 0.347 & 0.373 \\
Sable & 1390 & $620-2160$ & 3.5 & 0.337 & $\ldots$ \\
Tsessebe & 710 & $260-1100$ & 4.3 & 0.288 & $\ldots$ \\
Eland & 520 & $290-900$ & 3.2 & 0.343 & $\ldots$ \\
Roan & 250 & $35-380$ & 10.8 & 0.379 & $\ldots$ \\
Rare antelope $\neq$ & 2870 & $1200-4540$ & 3.5 & 0.302 & 0.501 \\
\hline
\end{tabular}

Note: Data are the range and coefficient of variation (CV) in census totals over the period 1960 1995 , together with the coefficient of variation in their proportional representation in kills ascribed to lions.

$\dagger$ The ratio of highest to lowest population size.

\$ Including sable, tsessebe, eland, and roan. 

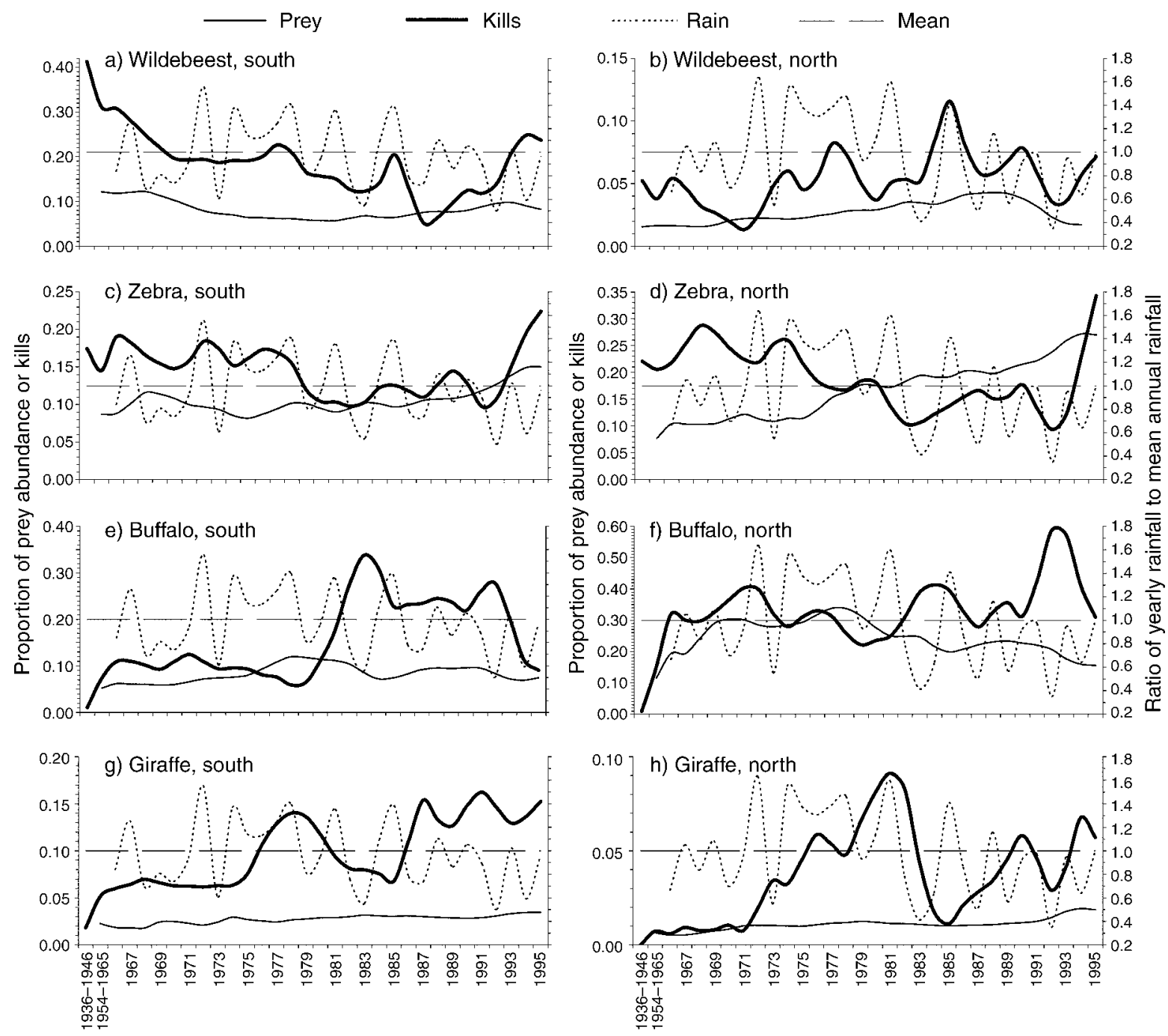

FIG. 2. Trends in the relative abundance of different ungulate species as available prey, compared with their proportional representation in kill records for lions and with the annual rainfall total: (a) wildebeest, south; (b) wildebeest, north; (c) zebra, south; (d) zebra, north; (e) buffalo, south; (f) buffalo, north; (g) giraffe, south; (h) giraffe, north; (i) kudu, south; (j) kudu, north; (k) waterbuck, south; (l) waterbuck, north; (m) impala, south; (n) impala, north; (o) warthog, whole park; (p) rare antelope species (sable, tsessebe, eland, and roan) combined, whole park.

National Parks internet data depository for the Kruger National Park. ${ }^{4}$

To establish how strongly changing prey selection by lions influenced the dynamics of the various herbivore populations, we assessed the correlations between annual population growth and selection ratio estimates, using the smoothed annual values in this case. Population growth was calculated as $\log _{e}\left(N_{t} / N_{t-1}\right)$, where $N_{t}=$ the population total in year $t$. The same $\log _{e}$ transformation was applied to the estimated selection values. Again, because the data used are not independent, $P$ values should be interpreted judiciously.

\footnotetext{
${ }^{4}\langle$ http://dataknp.sanparks.org/knp/〉
}

\section{Results}

\section{Variation in prey populations and kill proportions}

The number of kill records ascribed to lions amounted to $>1000$ annually between 1966 and 1970, dropping to $<400$ after 1974 , and $<250$ annually in most years from 1984 onwards (Fig. 1). Records for 1986 were missing. There were about twice as many kill records for lions from the southern half of the park compared with the northern section. The widest variability in proportional representation in recorded kills was shown by the rare antelope species, followed by buffalo and kudu (Table 1). Zebra and waterbuck showed the most constant proportions. Although the principal prey species, i.e., wildebeest, zebra, and buffalo, tended to show less 

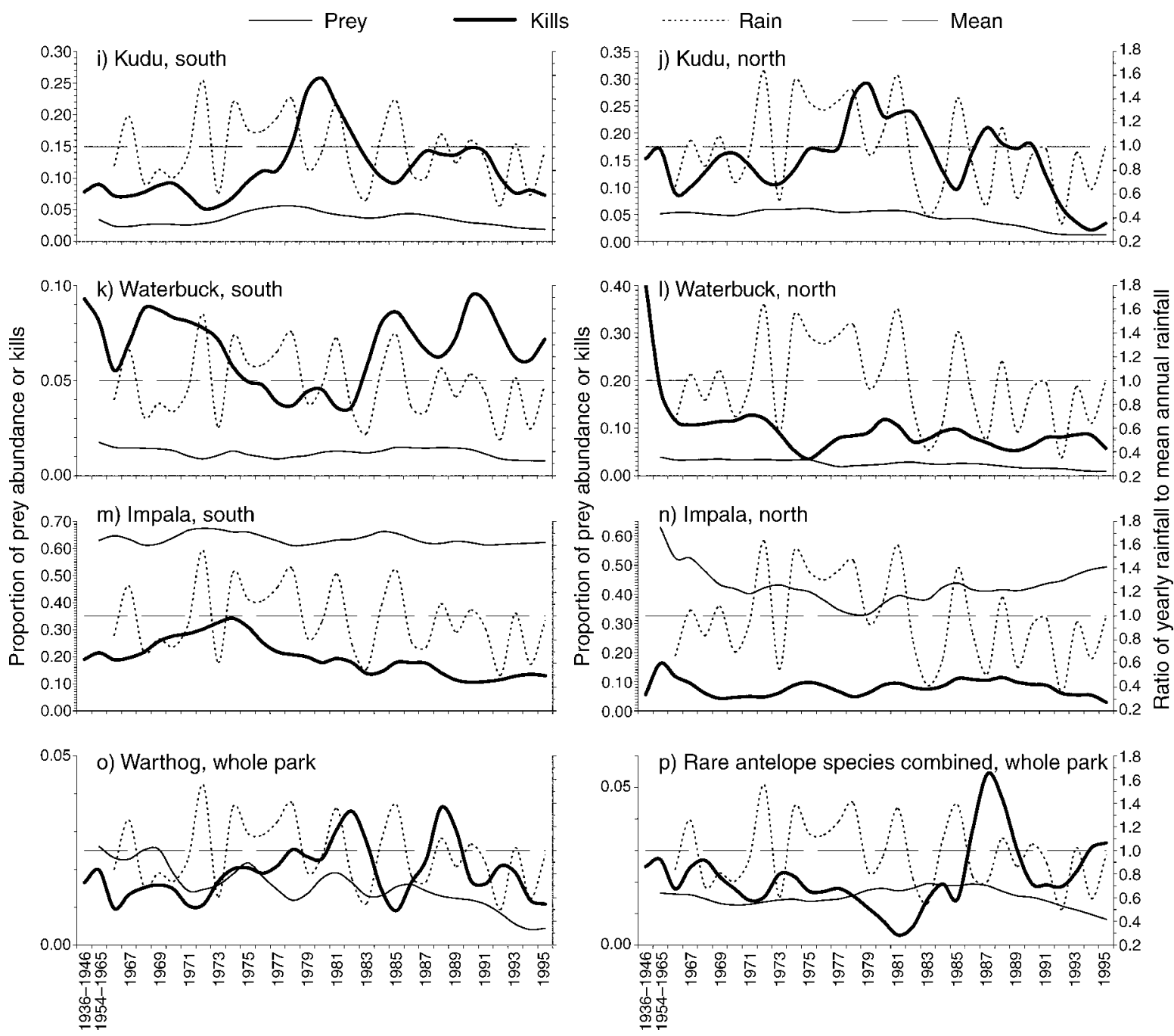

FIG. 2. Continued.

variation in population counts than alternative prey species, there was no clear distinction (Table 1). Impala, numerically the most abundant species, appeared most stable in count total over the period covered, with a less than twofold range of variation. For buffalo and zebra, the population variation was largely in the form of a progressive rise in abundance from 1960 until around 1990, which took place more slowly for zebra than for buffalo. The giraffe population also increased, but more steadily. Along with giraffe, the less common ungulate species showed the greatest variations in abundance, over a 3-10 fold range. This was due to a marked decline in the populations of the latter species from 1986 through to 1995.

Wildebeest and zebra, together with impala, constituted the main prey species of lions numerically in the southern half of KNP from 1946 through the early 1970s, making up 70-80\% of recorded kills (Fig. 2). Kudu and buffalo contributed 5-10\% and other species less. In the northern section of the park, buffalo and zebra made up 55-65\% of kills, and wildebeest, being uncommon, contributed little. Prior to 1946, buffalo did not feature in kills recorded in either part of the park, and waterbuck appeared to be the principal prey in the north.

Wildebeest and zebra both declined in their contribution to lions kills in the south after 1977. This was associated with a rise in the proportions constituted by kudu and giraffe initially, and then a huge increase in the contribution by buffalo, from $\sim 5 \%$ to $>30 \%$, during the 1982-1983 drought (Fig. 2). Buffalo remained more important numerically in kills than either wildebeest or zebra through the severe 1992 drought, but thereafter faded, following a decline in their population, with wildebeest and zebra becoming ascendant again. Associated with the increased contribution by buffalo was a decreased contribution by impala. 


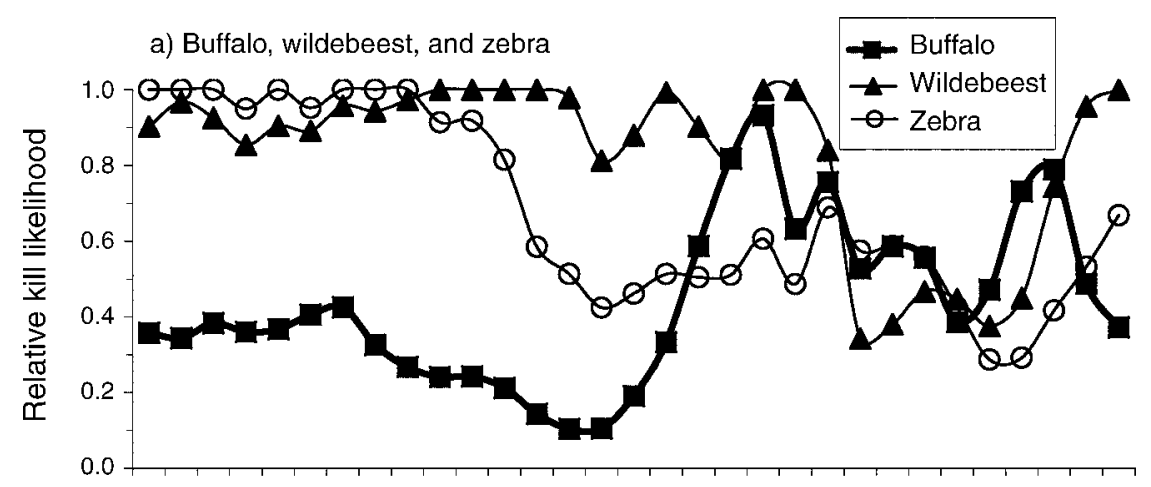

b) Giraffe, and kudo plus waterbuck combined
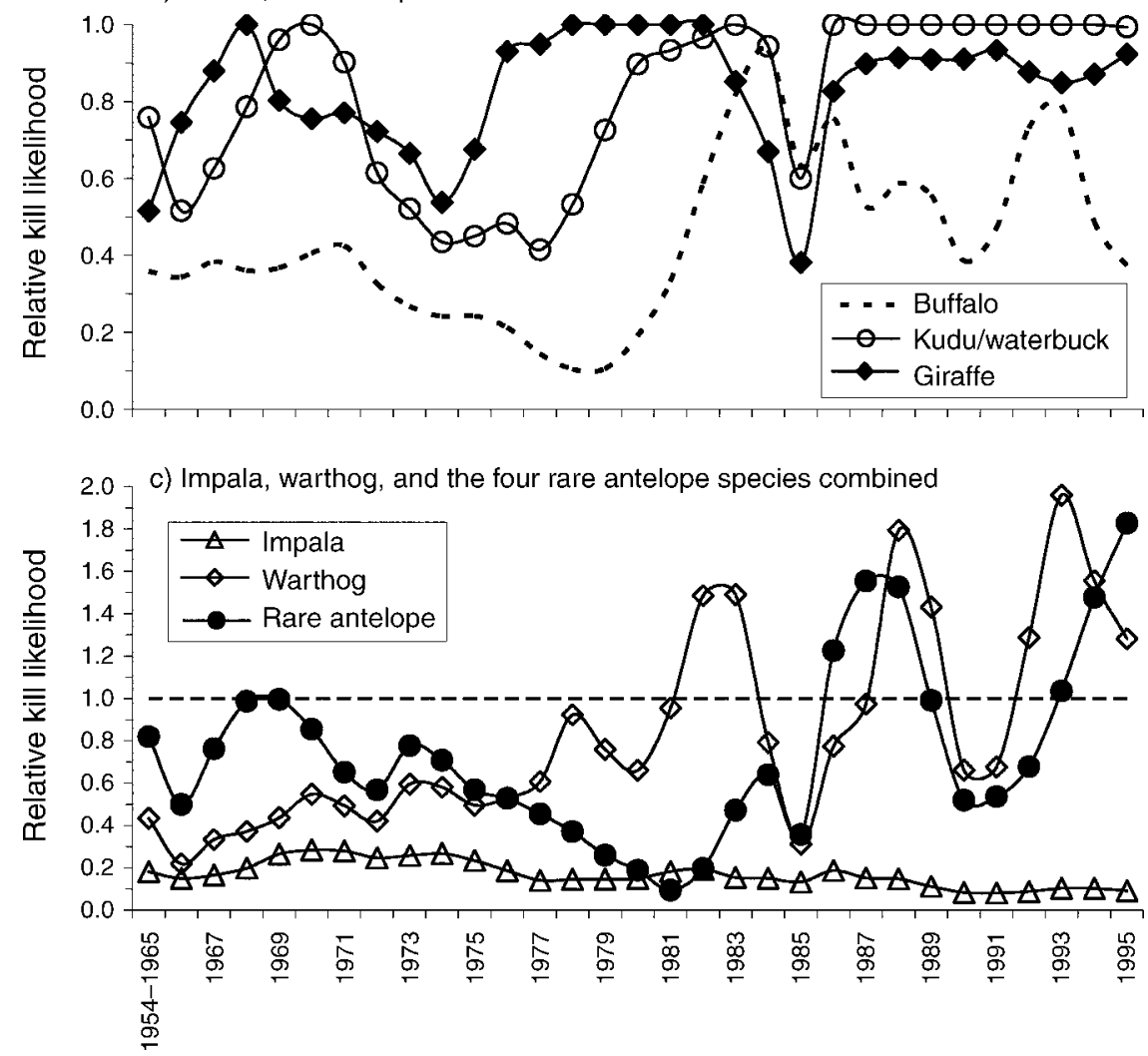

FIG. 3. Trends in relative kill likelihood by lions for different prey species, derived from the ratio between their proportions in the prey base and in the kill records across the whole park, corrected for biases: (a) buffalo, wildebeest, and zebra; (b) kudu plus waterbuck combined and giraffe [buffalo trace from (a) shown for comparison]; and (c) impala, warthog, and rare antelope species (sable, tsessebe, eland, and roan).

In the northern half of KNP, the kill contribution by buffalo was less variable, but with surges evident during both the 1982-1983 and 1992 droughts (Fig. 2). Buffalo constituted $>50 \%$ of the prey killed by lions during the latter period. The prey contribution by zebra in the north declined progressively from the mid-1970s through into the 1990s, despite their steady expansion in abundance in this region. The proportion of zebra in recorded kills rose following the drop in the buffalo population after 1992.
The rare antelope species as a group made a very small numerical contribution to recorded kills until ca. 1987, when their proportion rose abruptly from $<2 \%$ to $\sim 5 \%$. Eland rather than the numerically more abundant sable predominated in these records.

\section{Changing relative prey selection}

Wildebeest and zebra appeared to be the prey species most consistently favored by lions through the early portion of the study period, with buffalo somewhat less likely to be killed (Fig. 3). However, relative selection for 
zebra over the whole park declined after 1975 to about half that for wildebeest. Selection for buffalo rose abruptly during the 1982-1983 drought. Thereafter, following decreased selection for wildebeest, the three principal prey species showed very similar likelihoods of being predated. However, after 1986, kudu, waterbuck, and giraffe became more strongly favored as prey than the three principal species. Nevertheless, the rare antelope species appeared to be the most strongly selected prey for four consecutive years, from 1986 through 1989. After the 1992 drought, selection for wildebeest and zebra rose again, associated with declining selection for buffalo, but with the rare antelope species once again highly favored during this period. Relative selection for warthog peaked during the 19821983 drought, and resembled the pattern shown by the rare antelope species thereafter. In contrast, the relative likelihood of an impala being killed by lions remained consistently low throughout the study period, while fluctuating over a twofold range.

\section{Factors influencing prey susceptibility}

Model fitting indicated that selection by lions for wildebeest depended positively on the current annual rainfall and negatively on the abundance of buffalo, but was unaffected by the abundance of wildebeest themselves (Table 2). Selection by lions for zebra generally depended negatively on the own abundance of zebra, but was affected negatively by the abundance of buffalo only in the southern half of the park. An additional positive effect of rainfall was significant only for the south, and shallower and less consistent for zebra than for wildebeest (Fig. 4a, b). Furthermore, the degree of selection shown by lions for zebra was on average lower in the north of the park than in the south (Table 2).

Selection by lions for buffalo was strongly inversely dependent on rainfall averaged over the preceding three years, and negatively influenced by the abundance of zebra, but with a regional distinction evident (Table 2). The negative effect of zebra abundance on selection for buffalo was evident in the south only following the 1982-1983 drought. The effect of rainfall on selection for buffalo appeared similar in both halves of the park (Fig. 4d). Two years appeared deviant in the south: 1979, when selection for buffalo appeared exceptionally low, and 1985, when the relative kill likelihood seemed atypically high despite above-average rainfall. Hence these two outlying years were excluded from the data for the statistical assessment. The selection ratio shown by lions for buffalo was significantly much greater over the period following the 1982-1983 drought than it had been before this drought (log-transformed value $0.317 \pm$ 0.035 vs. $0.047 \pm 0.034$ ). Correspondingly, a $50 \%$ elevation in the relative likelihood of a buffalo being killed, taking into account rainfall, was evident after 1981, with 1985 excluded as an outlier (Fig. 4e).

Selection for giraffe appeared positively related to the abundance of buffalo, but uninfluenced by anything else
(Table 2). Selection for kudu depended negatively on the own abundance of kudu and positively on the abundance of buffalo, with no regional distinction and little or no additional influence from rainfall. Selection for waterbuck depended negatively both on rainfall (averaged over three years) and on the own abundance of waterbuck, and appeared to be influenced positively by the abundance of zebra in the south. Waterbuck were also generally more strongly favored by lions as prey in the south than in the north. For kudu plus waterbuck combined, selection by lions seemed to be negatively affected by rainfall only in the southern half of the park (Fig. 4c). Selection by lions for the rare antelope species was influenced negatively by the abundance of buffalo in the north of the park, and positively by the abundance of zebra in the south (Table 2).

\section{Influence of prey selection on population trend}

Changing predation pressure, as indexed by prey selection ratios for lions, evidently affected the population dynamics of kudu, waterbuck, warthog, and the rarer antelope among the alternative prey species, but only buffalo among the principal prey species (Table 3 ). For impala the effect was opposite to that expected, and restricted to the north of the park.

\section{DisCUSSION}

The records of lion kills reveal wide variation in the proportional representation of different prey species over time. These shifts in prey selection by lions appeared dependent both on the changing relative abundance of these herbivore species, and on the prevailing rainfall conditions. For at least some of the species, population trends seemed to be influenced by changing predation pressure.

\section{Predation-prompted declines by alternative prey species}

Findings provide clear evidence of a marked shift in prey selection by lions towards the rarer antelope species as a group around 1987 when their populations started declining precipitously, and again when these declines continued following the 1992 drought. The 2-3 fold increase in relative prey selection for these species was adequate to explain the similar rise in adult mortality observed after 1986 (Harrington et al. 1999, OwenSmith and Mason 2005). Moreover, the effect of changing prey selection by lions on population dynamics appeared strongest for these species. However, kills records were too sparse to distinguish the effects among the four prey species in this category. The shift by lions toward the rarer antelope species appeared to be prompted by the reduced abundance and hence lower vulnerability of buffalo as prey following the 1982-1983 drought, coupled with reduced susceptibility of wildebeest and zebra over the period of low rainfall that set in during 1987. With all three principal prey species less readily available, lions turned toward all alternative prey species, including kudu, waterbuck, warthog, and 
TABLE 2. Statistical parameters for factors potentially influencing the selection ratio for lions for each prey species.

\begin{tabular}{|c|c|c|c|c|c|c|c|c|}
\hline \multirow[b]{3}{*}{ Prey } & \multirow{2}{*}{\multicolumn{2}{|c|}{$\begin{array}{c}\text { Selection ratio } \\
\text { Regional contrasts }\end{array}$}} & \multicolumn{6}{|c|}{ Regression relationships } \\
\hline & & & \multicolumn{2}{|c|}{ Rainfall } & \multicolumn{2}{|c|}{ Own abundance } & \multicolumn{2}{|c|}{ Buffalo abundance } \\
\hline & Mean $\pm \mathrm{SE}$ & $P$ & Coeff. \pm SE & $P$ & Coeff. \pm SE & $P$ & Coeff. $\pm \mathrm{SE}$ & $P$ \\
\hline Wildebeest & $0.310 \pm 0.032$ & 0.740 & $0.70 \pm 0.18$ & $1 \mathrm{yr}:<0.001$ & $\ldots$ & 0.736 & $-0.29 \pm 0.12$ & 0.016 \\
\hline Zebra & $\begin{array}{r}\text { S: } 0.130 \pm 0.026 \\
\text { N: } 0.041 \pm 0.049\end{array}$ & 0.010 & $\mathrm{~S}: 0.38 \pm 0.15$ & $1 \mathrm{yr}: 0.022$ & $-0.40 \pm 0.10$ & $<0.001$ & $\mathrm{~S}:-0.30 \pm 0.08$ & 0.001 \\
\hline Buffalo & $\begin{array}{r}\text { S: } 0.208 \pm 0.050 \\
\text { N: } 0.128 \pm 0.032\end{array}$ & 0.007 & $-1.36 \pm 0.26$ & $3 \mathrm{yr}:<0.001$ & $\ldots$ & 0.372 & $\ldots$ & $\cdots$ \\
\hline Giraffe & $0.503 \pm 0.034$ & 0.126 & $\cdots$ & 2 yr: 0.187 & $\cdots$ & 0.630 & $0.32 \pm 0.14$ & 0.026 \\
\hline Kudu & $0.488 \pm 0.028$ & 0.782 & $\ldots$ & 1 yr: 0.140 & $-0.32 \pm 0.09$ & $<0.001$ & $0.78 \pm 0.12$ & $<0.001$ \\
\hline Waterbuck & $\begin{array}{r}\text { S: } 0.724 \pm 0.035 \\
\text { N: } 0.523 \pm 0.049\end{array}$ & $<0.001$ & $-0.95 \pm 0.42$ & 3 yr: 0.002 & $-0.26 \pm 0.13$ & 0.006 & $\cdots$ & 0.697 \\
\hline Rare antelope & $\begin{array}{r}\text { S: } 0.280 \pm 0.050 \\
\text { N: } 0.090 \pm 0.055\end{array}$ & 0.019 & $\cdots$ & 0.203 & $\cdots$ & 0.479 & $\mathrm{~N}:-0.52 \pm 0.26$ & 0.058 \\
\hline
\end{tabular}

Notes: Data are (first column) mean selection ratio ( $\log _{10}$-transformed) with its standard error (SE), and (remaining columns) regression coefficients for each factor with standard errors, distinguished by region $(\mathrm{S}=$ south, $\mathrm{N}=$ north) if there was a significant contrast. $P$ values against a null hypothesis of no effect are indicated either for models including all significant factors, or marginal $P$ values for the factor when it was incorporated additionally into this model. Whether significant rainfall effects extended over 1,2 , or 3 years is indicated with the $P$ value. Coefficient of determination $R^{2}$ is for the model including the set of significant factors. For buffalo only, pre-1983 and post-1983 periods were also distinguished.

$\dagger$ For the buffalo vs. zebra abundance in the south of the park, only the post-1983 relationship was significant.

giraffe, as well as the rare antelope species. This explains the timing of the breakpoint in population trend by these species, except for giraffe, identified by Ogutu and Owen-Smith (2005). The initiation of this simultaneous downward trend had previously seemed puzzling through being associated with a less extreme rainfall deficit than had occurred in 1982-1983.

A shift in prey selection toward giraffe was evident in the mid-1970s, when the vulnerability of buffalo was low because of high rainfall, and the availability of wildebeest and zebra reduced by low abundance, but with little or no effect on the population trend of giraffe. The persistent concentration by lions on kudu and waterbuck after 1986 explains the steadily declining trend shown by the latter two species through that period. Although grouped for certain analyses, the patterns of prey selection for kudu and waterbuck were not identical, with the contribution by waterbuck to lion kills being more consistent, and that by kudu dependent more on the prevailing rainfall conditions.

Shifting prey selection by lions seems adequate to explain the marked population declines shown by the alternative prey species, without any need to invoke an additional contribution from increased lion abundance. However, these two interpretations are not independent. An increase in the presence of lions in the regions where these prey species occur would generate an apparent shift in prey selection toward them, through raising the frequency of encounters between predator and prey, even if the likelihood of prey capture following an encounter remained unchanged. Hence our analysis of the prey kill records provides additional corroboration of the central role of changing predation risk in the declining trends shown by the alternative prey species, as had been proposed by Owen-Smith and Mills (2006).

\section{Rainfall-dependent predation on principal prey species}

The pattern identified previously by Smuts (1978) and Mills et al. (1995), with wildebeest and zebra more susceptible to being killed by lions during high rainfall conditions, and buffalo more vulnerable during dry years, was confirmed by our analysis. However, our wider data set revealed a marked and persistent shift in prey selection by lions toward buffalo in the south of KNP during and following the two consecutive drought years of 1982 and 1983. A greater susceptibility of buffalo, especially males, to being killed by lions during dry years when animals are in poor condition was noted by Funston et al. (2001). Much of the predation on buffalo in KNP and adjoining private reserves is by male lions preying on adult male buffalo (Funston et al. 1998, Radloff and du Toit 2004). The three-year influence of low rainfall suggests carryover effects on either animal condition or the state of the vegetation. Furthermore, the buffalo in the southern half of the park, but not in the north during our study period, had become chronically infected with bovine tuberculosis, which probably made an additional contribution to their vulnerability to both malnutrition and predation (Caron et al. 2003). The peak in the prey contribution by buffalo in the north of KNP around the time of the 1992 drought was associated with an outbreak of anthrax in this region, which added to the mortality incurred (Bengis et al. 2003). The low vulnerability of buffalo to being killed prior to 1982 was probably partly a result of the culling program, which held the buffalo population somewhat below the food ceiling set by rainfall, and restricted the number of animals surviving to old age. Having learned to hunt buffalo successfully during the drought period when they were vulnerable, lions in the south continued to concentrate more strongly on this 
TABLE 2. Extended.

\begin{tabular}{ccc}
\hline \hline \multicolumn{2}{c}{ Regression relationships } \\
\hline \multicolumn{2}{c}{ Zebra abundance } & $R^{2}$ \\
\hline Coeff. \pm SE & $P$ & 0.273 \\
$\ldots$ & 0.712 & 0.683 \\
$\ldots$ & $\cdots$ & 0.602 \\
S post: $-2.05 \pm 0.51 \dagger$ & 0.018 & 0.089 \\
N: $-0.29 \pm 0.19$ & 0.003 & 0.427 \\
$\ldots$ & 0.548 & 0.390 \\
$\ldots$ & 0.988 & 0.185 \\
S: $0.53 \pm 0.24$ & 0.041 & \\
S: $0.75 \pm 0.34$ & 0.040 &
\end{tabular}

prey species than before. However, after the buffalo population had incurred high mortality, the survivors were probably the more healthy individuals, deflecting predation pressure toward the alternative prey species. Kudu and waterbuck likewise seemed more vulnerable to malnutrition and hence to predation during periods of low rainfall (Owen-Smith 1990, Owen-Smith and Mills 2006).

Stevenson-Hamilton (1947) described contrasting oscillations in the relative abundance of predators and prey in KNP, extending from the 1920s through the 1940 s, although population counts are lacking to support his impression. He suggested that the concentration of water-dependent species around remaining surface water increased their vulnerability to predation during dry periods, while lions suffered during wet conditions when their prey became more widely dispersed. This interpretation seems to contradict the rainfall influence that we identified for wildebeest and zebra, the major prey species at that time. Nevertheless, in unpublished reports, Stevenson-Hamilton noted that wildebeest showed high mortality between 1916 and 1924 when rainfall had been high, and suffered much less mortality than other ungulate species during the extended drought conditions of the 1930s (cited by Whyte and Joubert 1988). Buffalo were virtually ignored by lions as prey during these early years.

Census figures indicate that fluctuations in the abundance of wildebeest, apparently associated with a cyclic component in the regional rainfall pattern (Tyson 1986), continued into our study period, with high numbers prevailing at the end of the dry period of the late 1960s, and low numbers through the wet period of the 1970s. Smuts (1978) suggested that the taller grass cover prevalent in high rainfall years provided more concealment for predators, and that wildebeest also became more vulnerable because herds were more widely dispersed through lion territories under such conditions. He acknowledged the possibility that taller grass could also be lower in nutritional value for wildebeest. However, the lack of any carryover effect of rainfall from prior years on the kill likelihood for wildebeest suggests that their vulnerability to predation is not nutritionally related.

For zebra, counts suggest that oscillatory dynamics continued through the 1970s, but thereafter zebra numbers increased progressively to unprecedented high levels, especially in the north of the park. This latter trend was associated with a reduced likelihood of zebra falling prey to lions compared with earlier years. The expansion in the zebra population is probably partly a consequence of widened provision of surface water through the construction of numerous boreholes and dams (Grant et al. 2002, Redfern et al. 2003, OwenSmith and Mills 2006), enabling zebras to disperse into areas where there were fewer lions (Harrington et al. 1999).

The greater vulnerability of buffalo to being killed by lions during dry periods after 1981, coupled with the expansion in the zebra population as well as in the abundance of giraffe, meant that the amount of food available to lions more than doubled compared with what it had been earlier (Owen-Smith and Mills 2006). There is supporting evidence that the abundance of lions expanded as a result (Owen-Smith and Mills 2006; see also Harrington et al. 1999). Furthermore, rather than cycling in response to the changing vulnerability of wildebeest and zebra, the lion population could potentially persist at a high level after this time due to the availability of abundant alternative prey in the form of buffalo during dry years.

\section{Functional response patterns}

Theory suggests that selection for principal prey species should be positively related to the abundance of these species, at least toward lower abundance levels, while selection for alternative prey should be negatively related to the abundance of the principal or preferred species (Joly and Patterson 2003). We did not find these patterns. Selection for zebra appeared negatively related to their own abundance, and selection for wildebeest and buffalo unrelated to own abundance. Selection for both wildebeest and zebra tended to be negatively related to the abundance of buffalo, independent of the rainfall influence, suggesting compensatory diet choice by lions. However, selection for giraffe and kudu among the alternative species was positively related to the abundance of buffalo, while that for waterbuck was positively related to the abundance of zebra. These contradictory patterns probably arose because rainfall conditions controlled abundance levels as well as the relative vulnerability of these prey species.

A shift in prey selection toward zebra was evident toward the end of the study period after zebra had attained high abundance. This may have contributed to the density-related reduction in the survival rate of adult zebra noted by Owen-Smith et al. (2005), and the curtailment of further population growth. The expansion in the distribution of zebra following augmentation 

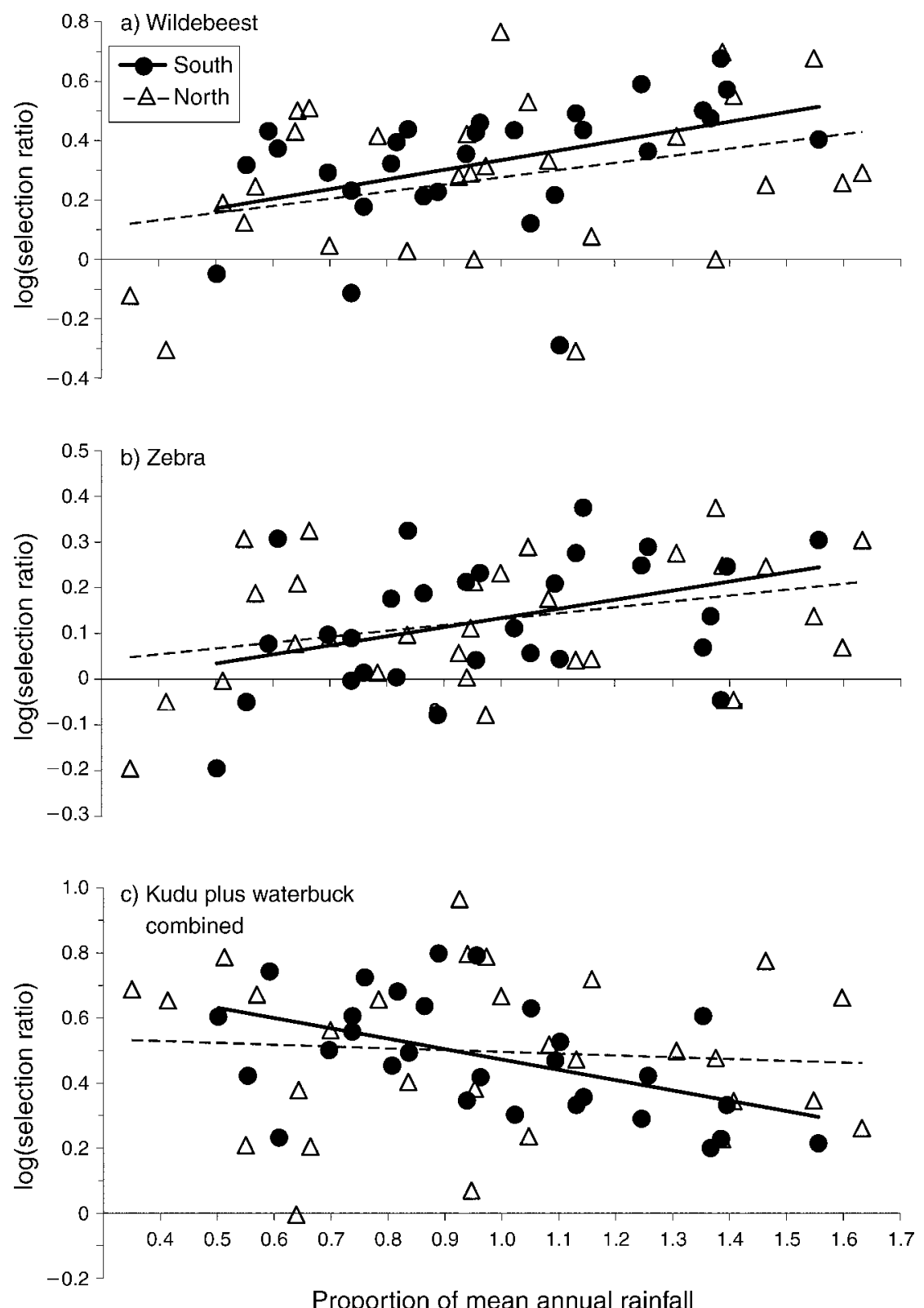

FIG. 4. Relationship between selection by lions for particular prey species and rainfall, comparing north and south halves of the park, for (a) wildebeest, (b) zebra, (c) kudu plus waterbuck combined, and (d) buffalo; and for (e) buffalo, comparing the periods before and following the 1982-1983 drought. Selection ratio is the proportion of species in kills divided by proportion of species among available prey. Relative kill likelihood is the selection ratio adjusted relative to that of most favored prey species.

of surface water supplies probably enabled them to keep ahead of the follow-up increase in lion abundance up to that time (Harrington et al. 1999, Owen-Smith and Mills 2006).

While the increase in relative prey selection by lions for the rarer antelope species suggests that a functional rather than numerical predator response was responsible for the population declines shown by these species, both aspects potentially contributed to selection ratio estimates. An increase in the abundance of lions in the regions where these localized species occur, enabled by the provision of surface water and consequent increase in availability of zebra, raises the probability that lions will encounter one of the rarer antelope species while hunting. This effect is independent of any change in the populations of these rarer species, or in the probability of a kill being made following an encounter.

\section{Population impacts}

The population trends of all of the less common ungulate species that declined severely in abundance after 1986 were evidently strongly affected by changing 

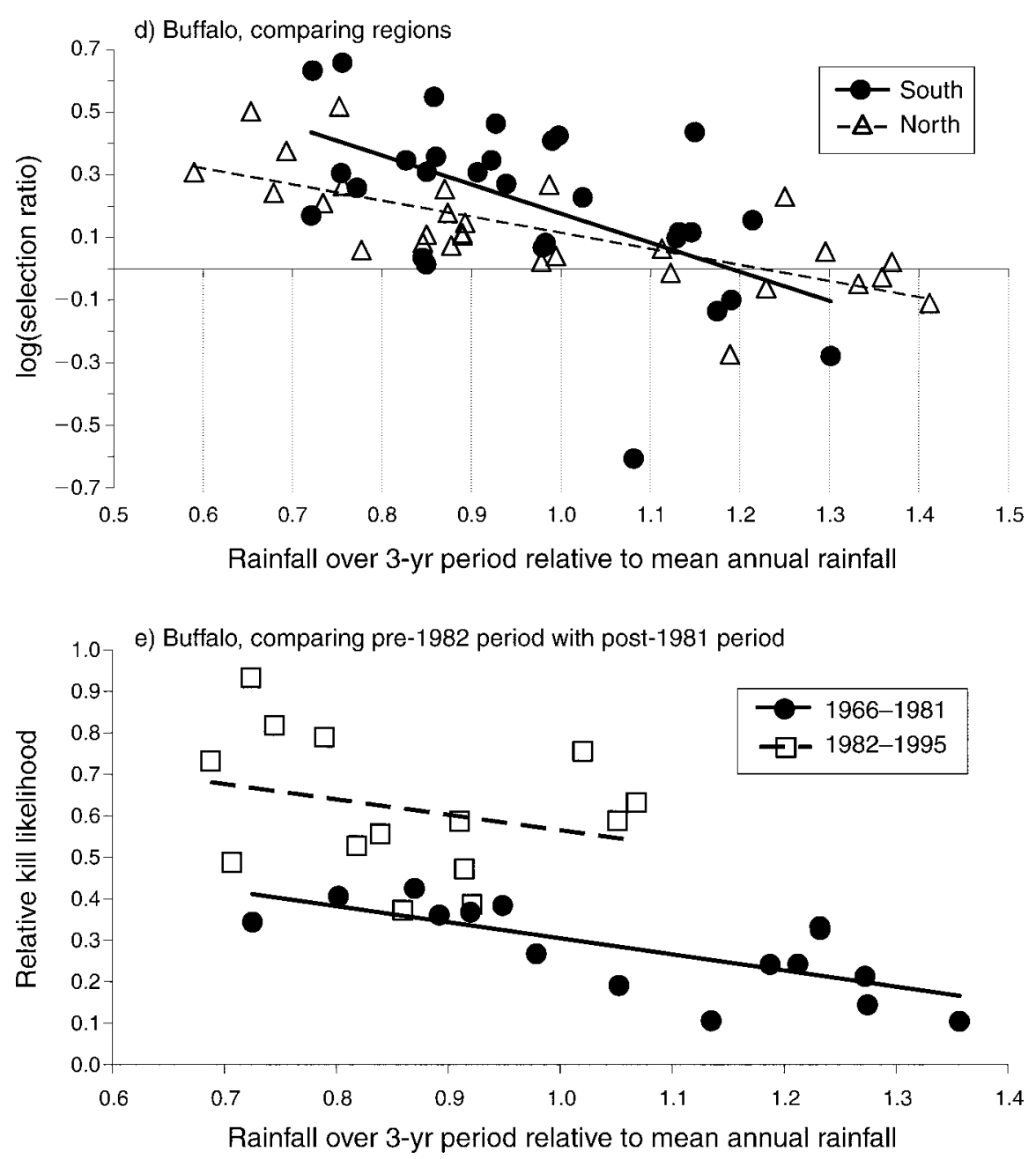

FIG. 4. Continued.

predation pressure. Changes in the abundance of buffalo were apparently also influenced by changing prey selection by lions, but in their case vulnerability to predation cannot be disentangled from susceptibility through food deficiencies, and possibly also disease. However, the population dynamics of wildebeest and zebra seemed to be unaffected by changing predation levels, despite the effect of rainfall on vulnerability to predation.

The strange positive influence of lion predation on population growth by impala is probably related to the greater impact of other predators on impala dynamics.
Impala constitute the principal prey species for spotted hyena, leopard, cheetah, and wild dog (Owen-Smith and Mills 2008). Although impala were numerically abundant in their kills, lions showed a low selection for impala, and impala made a relatively minor contribution to the food intake of lions in mass terms (Owen-Smith and Mills 2008). The reduced tendency by lions to prey on impala during the latter portion of the study period was counteracted by slightly elevated predation by leopard and cheetah, although apparently not by wild $\operatorname{dog}(\mathrm{N}$. Owen-Smith, unpublished data). However, the wild dog population has fluctuated quite widely in KNP

TABLE 3. Correlation coefficients $(r)$ between annual population growth and prey selection ratios for lions derived from kill records for ungulate species in the Kruger National Park.

\begin{tabular}{|c|c|c|c|c|c|c|c|c|c|}
\hline Region & $\begin{array}{c}\text { Wilde- } \\
\text { beest }\end{array}$ & Zebra & Buffalo & Impala & Giraffe & Kudu & Waterbuck & Warthog & Rare antelope \\
\hline Park & -0.087 & 0.122 & $-0.502(0.034)$ & $0.448(0.062)$ & 0.079 & $-0.480(0.044)$ & $-0.595(0.009)$ & $-0.688(0.002)$ & $-0.797(<0.001)$ \\
\hline South & 0.139 & 0.351 & $-0.498(0.036)$ & -0.066 & -0.358 & $-0.459(0.056)$ & $-0.548(0.019)$ & $\cdots$ & $\cdots$ \\
\hline North & 0.003 & 0.343 & $-0.753(0.001)$ & $0.438(0.069)$ & 0.347 & -0.332 & -0.379 & $\cdots$ & $\cdots$ \\
\hline
\end{tabular}

Note: Associated $P$ values (in parentheses) are included only if $P<0.10$. 
(Buettner et al. 2006), with high numbers during low rainfall years intensifying predation on impala, while low numbers during high rainfall years reduced predation. Being subject to adaptive responses by many predator species perhaps contributed to the narrower range of variation in the abundance of impala, compared with other herbivore species in KNP. The main role of predator diversity thus seems to be to increase regulatory control of the prey population, rather than to accentuate predation pressure as suggested by Sinclair et al. (2003) for the Serengeti ecosystem.

\section{Comparison with other ecosystems}

Relatively few studies have analyzed changing patterns of predation in multi-prey species systems, largely because of the challenge of collecting sufficient data on all of the species concerned. In the Serengeti, predation contributed a much lesser proportion of the mortality of buffalo and giraffe than it did for wildebeest, zebra, and other medium-sized ungulates (Sinclair et al. 2003). Lions turned to buffalo and other resident species after concentrations of the migratory wildebeest and zebra had temporarily moved away (Scheel 1993, Scheel and Packer 1995). Several of the less common ungulate species, including topi (Damaliscus lunatus), impala, and warthog, increased greatly in abundance in northern Serengeti following the elimination of most large carnivores, as well as most of the buffalo, by poaching or poisoning (Sinclair et al. 2003).

In Glacier National Park, predation by wolves (Canis lupus) had little influence on the abundance of moose (Alces alces), the largest and hence least vulnerable prey species, while an increase in the abundance of wolves was associated with declines in the abundance of elk (Cervus canadensis) and white-tailed deer (Odocoileus virginianus [Kunkel and Pletcher 1999]). In the Bialowieza Forest, spanning the border between Poland and Belarus, where five ungulate species were available as prey for wolves, the contribution of other prey depended on the abundance of the staple prey species, red deer (Cervus elaphus [Jedrzejewski et al. 2000]).

\section{Contrasting dynamics by different prey species}

In KNP, shifting prey selection by lions apparently influenced the dynamics of prey populations in the following ways:

1) Cyclic variation in abundance over a twofold range by wildebeest, driven by shifting vulnerability to predation related to rainfall conditions (Smuts 1978, Ogutu and Owen-Smith 2005);

2) A progressive expansion in the abundance of zebra, apparently as a consequence of lowered exposure to predation following widened surface water availability (Owen-Smith and Mills 2006);

3) Greater susceptibility of buffalo to predation under dry conditions, probably predisposed by malnutrition, promoting irregular fluctuations in abundance;
4) A shift by lions toward alternative less common prey species at times when the principal prey species became less vulnerable or less available, temporarily depressing the abundance of the former;

5) Drastic declines in populations of rarer prey species, precipitated by a spatial shift in predation toward them during a period when most alternative prey were less available;

6) A relatively stable abundance level maintained by impala, the herbivore species subject to predation by the widest range of predators.

These findings demonstrate that simple predator-prey theory based on functional and numerical responses to changing relative prey abundance is an inadequate framework for interpreting the dynamics of multi-prey systems. Environmental conditions affect the relative susceptibility of herbivore species to predation, not only through food deficiencies, but also through habitat cover affecting exposure. Shifts in the relative distribution of the principal and alternative prey species, and consequences of past mortality for demographic structure, have additional effects. Hence adaptive responses by predators to changing relative prey abundance, accessibility, and vulnerability must be taken into account in order to interpret prey population trends within multispecies predator-prey webs.

\section{ACKNOWLEDGMENTS}

We are indebted to the numerous field rangers who assembled the predator kill records. Jackie Mahnecke extracted part of the data from the park files, while J. W. Cain suggested improvements to the statistical treatment. J. T. du Toit, Atle Mysterud, and an anonymous reviewer contributed toward general improvements of the manuscript.

\section{Literature Cited}

Ballard, W. B., D. Lutz, T. W. Keegan, L. H. Carpenter, and J. C. deVos. 2001. Deer-predator relationships: a review of recent North American studies with emphasis on mule and black-tailed deer. Wildlife Society Bulletin 29:99-115.

Bengis, R. G., R. Grant, and V. de Vos. 2003. Wildlife diseases and veterinary controls: a savanna ecosystem perspective. Pages 349-369 in J. T. du Toit, H. C. Biggs, and K. H. Rogers, editors. The Kruger experience: ecology and management of savanna heterogeneity. Island Press, Washington, D.C., USA.

Bergerud, A. T., and J. P. Elliot. 1986. Dynamics of caribou and wolves in northern British Columbia. Canadian Journal of Zoology 64:1515-1529.

Buettner, U. K., H. T. Davies-Mostert, J. T. du Toit, and M. G. L. Mills. 2006. Factors affecting juvenile survival in African wild dogs (Lycaon pictus) in Kruger National Park, South Africa. Journal of Zoology 272:10-19.

Caron, A., P. C. Cross, and J. T. du Toit. 2003. Ecological implications of bovine tuberculosis in African buffalo herds. Ecological Applications 13:1338-1345.

Chesson, J. 1978. Measuring preference in selective predation. Ecology 59:211-215.

Chesson, J. 1983. The estimation and analysis of preference and its relationship to foraging models. Ecology 64:1297-1304.

de Ruiter, P., V. Wolters, and J. Moore, editors. 2005. Dynamic food webs. Multispecies assemblages, ecosystem development and environmental change. Academic Press, Burlington, Massachusetts, USA. 
Fryxell, J. M., J. Greever, and A. R. E. Sinclair. 1988. Why are migratory ungulates so abundant? American Naturalist 138: 781-798.

Fryxell, J. M., and P. Lundberg. 1994. Diet choice and predator-prey dynamics. Evolutionary Ecology 8:407-421.

Funston, P. J., and M. G. L. Mills. 2006. The influence of lion predation on the population dynamics of common large ungulates in the Kruger National Park. South African Journal of Wildlife Research 36:9-22.

Funston, P. J., M. G. L. Mills, and H. C. Biggs. 2001. Factors influencing the hunting success of male and female lions in the Kruger National Park. Journal of Zoology 253:419-431.

Funston, P. J., M. G. L. Mills, H. C. Biggs, and P. R. K. Richardson. 1998. Hunting by male lions: ecological influences and socioecological implications. Animal Behaviour 56: $1333-1345$.

Grange, S., and P. Duncan. 2006. Bottom-up and top-down processes in African ungulate communities: resources and predation acting on the relative abundance of zebra and grazing bovids. Ecography 29:899-907.

Grant, C. C., T. Davidson, P. J. Funston, and D. Pienaar. 2002. Challenges faced in the conservation of rare antelope: a case study on the northern basalt plains of the Kruger National Park. Koedoe 45:45-66.

Hanski, I., L. Hansson, and H. Henttonen. 1991. Specialist predators, generalist predators, and the microtine rodent cycle. Journal of Animal Ecology 60:353-367.

Harrington, R., N. Owen-Smith, P. C. Viljoen, H. C. Biggs, D. R. Mason, and P. J. Funston. 1999. Establishing the causes of the roan antelope decline in the Kruger National Park, South Africa. Biological Conservation 90:69-78.

Holt, R. D. 1977. Predation, apparent competition and the structure of prey communities. Theoretical Population Biology 12:197-229.

Jedrzejewski, W., B. Jedrzejewski, H. Okarma, K. Schmidt, K. Zub, and M. Musiani. 2000. Prey selection and predation by wolves in Bialowieza Primeval Forest, Poland. Journal of Mammalogy 81:197-212.

Joly, D. O., and B. R. Patterson. 2003. Use of selection indices to model the functional response of predators. Ecology 84 : $1635-1639$.

Joubert, S. C. J. 1983. A monitoring programme for an extensive national park. Pages 201-212 in R. N. Owen-Smith, editor. Management of large mammals in African conservation areas. Haum, Pretoria, South Africa.

Kunkel, K., and D. H. Pletscher. 1999. Species-specific population dynamics of cervids in a multipredator ecosystem. Journal of Wildlife Management 63:1082-1093.

Manly, B. F. J., L. L. McDonald, D. L. Thomas, T. L. McDonald, and W. P. Erickson. 2002. Resource selection by animals: statistical design and analysis for field studies. Second edition. Kluwer Academic, Norwell, Massachusetts, USA.

Matter, W. J., and R. W. Mannan. 2005. How do prey persist? Journal of Wildlife Management 69:1315-1320.

Messier, F. 1994. Ungulate population models with predation: a case study with the North American moose. Ecology 75: 478-488.

Mills, M. G. L., H. C. Biggs, and I. J. Whyte. 1995. The relationship between rainfall, lion predation, and population trends in African herbivores. Wildlife Research 22:75-88.

Ogutu, J. O., and N. Owen-Smith. 2005. Oscillations in large herbivore populations: Are they related to predation or rainfall? African Journal of Ecology 43:332-339.

Owen-Smith, N. 1990. Demography of a large herbivore, the greater kudu, in relation to rainfall. Journal of Animal Ecology 59:893-913.
Owen-Smith, N., and D. R. Mason. 2005. Comparative changes in adult versus juvenile survival affecting population trends of African ungulates. Journal of Animal Ecology 74:762-773.

Owen-Smith, N., D. R. Mason, and J. O. Ogutu. 2005. Correlates of survival rates for ten African ungulate populations: density, rainfall and predation. Journal of Animal Ecology 74:774-788.

Owen-Smith, N., and M. G. L. Mills. 2006. Manifold interactive influences on the population dynamics of a multispecies ungulate assemblage. Ecological Monographs 76:73-92.

Owen-Smith, N., and M. G. L. Mills. 2008. Predator-prey size relationships in an African large-mammal food web. Journal of Animal Ecology 77:173-183.

Pienaar, U. de V. 1963. The large mammals of the Kruger National Park - their distribution and present-day status. Koedoe 6:1-37.

Pienaar, U. de V. 1969. Predator-prey relationships among the larger mammals of the Kruger National Park. Koedoe 12: $108-176$.

Radloff, F. G. T., and J. T. du Toit. 2004. Large predators and their prey in a southern African savanna: a predator's size determines its prey size range. Journal of Animal Ecology 73: 410-423.

Redfern, J. V., C. C. Grant, H. C. Biggs, and W. M. Getz. 2003. Surface water constraints on herbivore foraging in the Kruger National Park, South Africa. Ecology 84:2092-2107.

Rutherford, M. C. 1980. Annual plant production-precipitation relations in arid and semi-arid regions. South African Journal of Science 76:53-56.

Scheel, D. 1993. Profitability, encounter rates and prey choice of African lions. Behavioral Ecology 4:90-97.

Scheel, D., and C. Packer. 1995. Variation in predation by lions: tracking a moveable feast. Pages $299-314$ in A. R. E. Sinclair and P. Arcese, editors. Serengeti II. University of Chicago Press, Chicago, Illinois, USA.

Schmitz, O. J. 1995. Functional responses of optimal consumers and the potential for regulation of resource populations. Wildlife Research 22:101-114.

Sinclair, A. R. E., and P. Arcese. 1995. Population consequences of predation-sensitive foraging: the Serengeti wildebeest. Ecology 76:882-891.

Sinclair, A. R. E., S. Mduma, and J. S. Brashares. 2003. Patterns of predation in a diverse predator-prey community. Nature 425:288-290.

Smuts, G. L. 1978. Interrelations between predators, prey, and their environment. BioScience 28:316-320.

SPSS. 1998. SYSTAT 8.0. SPSS, Chicago, Illinois, USA.

Stevenson-Hamilton, J. 1947. Wild life in South Africa. Cassel, London, UK.

Tyson, P. D. 1986. Climatic change and variability in southern Africa. Oxford University Press, Oxford, UK.

van Boalen, M., V. Krivan, P. C. J. van Rijn, and M. W. Sabelis. 2001. Alternative food, switching predators, and the persistence of predator-prey systems. American Naturalist 157:512-524.

Viljoen, P. C., and P. F. Retief. 1994. The use of the Global Positioning System for real-time data collected during ecological aerial surveys in the Kruger National Park, South Africa. Koedoe 37:149-157.

Whyte, I. J., and S. C. J. Joubert. 1988. Blue wildebeest population trends in the Kruger National Park and the effects of fencing. South African Journal of Wildlife Research $18: 78-87$.

Wittmer, H. U., A. R. E. Sinclair, and B. M. McLellan. 2005. The role of predation in the decline and extirpation of woodland caribou. Oecologia 144:257-267. 